\title{
Materiais manipuláveis e repertório compartilhado em aulas de matemática envolvendo tópicos de geometria
}

\section{Jamerson dos Santos Pereira}

Universidade Federal do Recôncavo da Bahia, Centro de Formação de Professores

pereirajamerson@hotmail.com

\section{Andréia Maria Pereira de Oliveira}

Universidade Federal da Bahia, Faculdade de Educação

ampo@ufba.br

\begin{abstract}
Resumo
Neste artigo, analisamos o repertório compartilhado no desenvolvimento de uma tarefa em aulas de Matemática que abordaram tópicos de geometria, na qual foram utilizados materiais manipuláveis. Utilizamos, como lente teórica na compreensão do objeto de estudo e discussão dos dados, a perspectiva da aprendizagem situada segundo Jean Lave e Etienne Wenger. Os dados foram coletados, principalmente, por meio da observação, entrevistas e registros dos estudantes. Os resultados apontam que os participantes apresentam modos compartilhados de participar, tornando comuns os elementos do repertório dispensado pela prática social. A partir da pesquisa, algumas situações de compartilhamento foram delineadas: compartilhamento de símbolos, expressões e termos geométricos e Tentativas compartilhadas de ajustar a fórmula do Teorema de Pitágoras.
\end{abstract}

Palavras-chave: Ensino de Geometria. Materiais manipuláveis. Repertório compartilhado.

\section{Manipulative materials and shared repertoire in mathematics lessons involving topics of geometry}

\begin{abstract}
In this paper, we analyze the shared repertoire in the development of one task in mathematics classes that addressed topics of geometry, in which were used manipulative materials. We used the Situated Learning Perspective as provided by Jean Lave and Etienne Wenger as theoretical lens to understand the object of study and the discussion of the data. Data were collected through mainly observation, interview and student records. The results show that the participants have shared ways to participate, making the common elements of the repertoire dispensed by its social practice. From the research, some sharing situations were outlined: Sharing symbols, expressions and geometric terms e Shared attempts to adjust the formula of the Pythagoras' theorem.
\end{abstract}

Keywords: Teaching Geometry. Manipulative Materials. Shared repertoire. 


\section{Introdução}

Os materiais didáticos têm sido foco de pesquisas em Educação Matemática (PAIS, 2000; CLEMENTS, 1999). Estas pesquisas, em sua maioria, discutem sobre as vantagens e as desvantagens da sua utilização no ensino de Matemática e outras, mais especificamente, no ensino de geometria. Nessa direção, alguns autores chamam atenção para o uso do material didático pautado numa reflexão antes de usá-lo em sala de aula (PAIS, 2000). Esses materiais, no sentido amplo, são recursos utilizados pelo professor, tais como livros, listas de exercício, jogos, materiais manipuláveis ou concretos, etc.

Adotaremos, a partir de agora, o termo materiais manipuláveis em convergência com Reys ${ }^{1}$ (1971 apud PASSOS, 2006), pois, de acordo com ele, os materiais manipuláveis são “objetos ou coisas que o estudante é capaz de sentir, tocar, manipular e movimentar. Podem ser objetos reais que têm aplicação no dia a dia ou podem ser objetos que são usados para representar uma idéia" (REYS, 1971 apud PASSOS, 2006, p. 78). Notemos, porém, que essa definição não faz referência às ideias estritamente matemáticas.

Os professores, em sua maioria, costumam acreditar que o fato de utilizar os materiais didáticos, em sala de aula, ameniza as dificuldades de ensino, pensando que o simples manuseio destes recursos acarretaria a compreensão dos conteúdos por parte dos estudantes (PASSOS, 2006, 2007). Entretanto, Pais (2000) salienta que o uso desses materiais didáticos no ensino de geometria deve ser pautado numa reflexão pedagógica, evitando, assim, que se recaia numa experiência desprovida de intenções pedagógicas. Os bons materiais, portanto, devem favorecer construção, fortalecimento e ligação entre várias ideias matemáticas (MOYER, 2001).

A dimensão concreta dos materiais manipuláveis é discutida por Clements (1999), por exemplo, quando ele associa esses recursos ao fato de eles poderem ser agarrados ou manipulados com as próprias mãos. De certo modo, suas ideias convergem com as de Reys (1971 apud PASSOS, 2006) no sentido de permitirem o toque, a manipulação, o movimento e, devemos acrescentar, o dobrar, frisar, recortar, sobrepor, justapor. Assim, ganham espaço, por exemplo, uma régua, uma tesoura, uma folha de papel ou garrafa plástica que não são especialmente construídos para trabalhar ideias matemáticas, mas que podem ser utilizados pelos estudantes e professores de modo a fomentar alguma compreensão matemática. Esses elementos podem ter a finalidade de ensino, mas a concretude das ações com eles dependem da relação que o estudante estabelece socialmente.

Nesse sentido, precisamos levar em consideração o contexto em que se utiliza o material manipulável como também as relações sociais estabelecidas pelos sujeitos. Assim, focaremos a

\footnotetext{
${ }^{1}$ REYS, R. E. Considerations for teaching using manipulative materials. The arithmetic teacher, v. 18, n. 8, p. 551$558,1971$.
} 
discussão no que tange aos materiais manipuláveis no contexto da prática social de estudantes do Ensino Fundamental II, em aulas de matemática, nas quais foram abordados dois tópicos de geometria: teorema de Pitágoras e ângulos fundamentais. Diante disso, analisaremos, então, como esses estudantes compartilham o repertório nas práticas das quais eles participam. Na seção seguinte, traremos, mais especificamente, da perspectiva teórica e de alguns conceitos que embasaram esta pesquisa.

\section{Prática social, participação e repertório compartilhado}

A prática social, conforme argumenta Wenger (1998), diz respeito a um fazer situado dentro de um contexto histórico e social que fornece estrutura e significado às nossas ações. Nesse movimento, são estabelecidas relações específicas entre os membros que compõem o grupo, formas de se relacionar particulares em cada contexto; ou seja, a linguagem, os símbolos, os instrumentos são específicos.

A prática social, nesse sentido, diz respeito às formas de agir que são compartilhadas direta ou indiretamente pelos grupos socialmente estabelecidos. Esse conceito de prática social está intimamente ligado ao de participação. Esse conceito, então, refere-se a um processo de estar envolvido ativamente nas práticas sociais (WENGER, 1998). Nesse sentido, Wenger (1998) aponta para a possibilidade de haver, nas relações sociais, reconhecimento mútuo, inclusive por parte de quem pratica a ação.

É importante destacar que as relações estabelecidas na prática social de um grupo não são, necessariamente, harmoniosas em todos os aspectos da prática. Participação, aliás, engloba todo tipo de relação, ou seja, envolve as relações competitivas, cooperativas ou conflituosas (WENGER, 1998). Compartilhar, nesse sentido, não remete, necessariamente, a concordar com tudo que é dito ou feito, mas sim tomar conhecimento de que o fato existe. Além disso, não consta nesta perspectiva a participação presencial dos membros, tampouco a definição clara de fronteiras do grupo (MATOS, 1999).

O conceito de participação não só está conectado ao de prática social, mas também ao de aprendizagem, que é caracterizado pela mudança de participação do indivíduo nas atividades vinculadas à prática (LAVE; WENGER, 1991). Nesse sentido, Frade (2003, p. 68) argumenta que, no processo de aprendizagem, o desenvolvimento de uma prática é caracterizado pela "capacidade de manter o engajamento de seus membros na perseguição de empreendimentos comuns". Aprendizagem, nesse sentido, tem a ver com estar engajado nos empreendimentos/objetivos comuns. 
Para tal, num grupo social, os membros necessitam desenvolver e utilizar meios, físicos ou não, que auxiliem sua prática; estes meios podem ser concebidos como ferramentas da prática. Estas devem ser entendidas como elementos/instrumentos auxiliadores da prática, da ação desenvolvida pelo grupo. Assim, uma tesoura, numa aula de Matemática, por exemplo, pode ter um significado; numa aula de Geometria, pode ter um sentido diferente. Assim, as ferramentas e seus significados dependem do contexto, das intencionalidades, ou seja, de seu uso nas práticas sociais.

Consequentemente, os materiais manipuláveis configuram-se como ferramentas disponíveis na prática e tem sua função definida pela dinâmica e estrutura desta. No entanto, as ferramentas nem sempre são físicas, pois a prática não é, necessariamente, caracterizada pelo uso de elementos manuseáveis (LAVE; WENGER, 1991). Assim, na prática em que se utilizam materiais manipuláveis podem existir meios não físicos que a subsidiam, como modos de falar, de agir, de interpretar, etc. Os sujeitos podem compartilhar um modo ímpar de se expressar do grupo e atribuem significado a vários elementos, ações e modos de se expressar vinculados à prática social. Isso gera compreensão comum à situação posta na prática (SANTOS, 2004). Esse processo de significação Wenger (1998) chama de negociação de significado.

Esse conceito diz respeito a um processo por meio do qual o indivíduo experimenta o mundo social e seu engajamento significativamente (WENGER, 1998). Nesse sentido, o significado não reside no indivíduo nem no mundo social, mas na relação variável que se estabelece com o mundo. Diante disso, o autor salienta que o engajamento humano no mundo é primariamente um processo de negociação de significados. Olhar a prática social, com utilização de materiais manipuláveis, sugere olhar para os termos empregados no decorrer da prática, o modo como os sujeitos usam os recursos. Por exemplo, manipular um triângulo de modo a associar um de seus lados ao lado de um quadrado sugere a criação de hipótese e utilização de parte de um material.

Wenger (1998) conceitua tal situação como repertório compartilhado, vislumbrando o arcabouço de ferramentas, linguagens, técnicas, ações e atividades disponíveis e compartilhadas. Beline (2012) salienta que a busca do desenvolvimento das tarefas de um grupo acarreta no desenvolvimento de alguns recursos físicos e simbólicos. O constructo teórico permitirá reconhecer e definir práticas compartilhadas mais adiante. Estas práticas compartilhadas podem ser muito bem entendidas como ações desenvolvidas pelo grupo durante as interações sociais. Isto sugere olhar os elementos não de forma isolada, mas fazendo parte e contribuindo com a prática de um grupo social.

Com isso, discutir repertório compartilhado numa prática em que se instala o uso de materiais manipuláveis, visando abordar algum tópico de geometria, é mais que tangenciar apenas a linguagem do grupo, diz respeito, também, à compreensão de seus modos de agir, pensar, 
argumentar, nomear elementos, nomear relações estabelecidas entre os membros e entre membros e o material manipulável; seus modos de criar e utilizar uma simbologia comum do/no grupo; entendendo, ainda, a negociação dos significados produzidos e/ou utilizados na prática.

\section{Contexto e método do estudo}

O contexto da produção de dados foi uma sala de aula do $8^{\circ}$ ano do Ensino Fundamental, da rede pública de Feira de Santana, Bahia, sendo utilizadas três aulas de 50 minutos para desenvolvimento de uma tarefa. Esta tarefa foi desenvolvida pelo Observatório de Educação Matemática da Bahia (OEM-Bahia).

A professora Lúcia, licenciada em Ciências e Matemática, lecionava na rede pública de ensino há 21 anos e integrava o projeto citado, foi convidada a participar da pesquisa. Ela desenvolveu uma tarefa que enfatizou as compreensões acerca do teorema de Pitágoras por meio de materiais manipuláveis. O kit do material manipulável constituía-se de quadrado amarelo $(3 \times 3 \mathrm{~cm})$, quadrado vermelho $(4 \times 4 \mathrm{~cm})$, quadrado azul $(5 \times 5 \mathrm{~cm})$ e triângulo retângulo $(3,4$ e $5 \mathrm{~cm})$. Para o desenvolvimento da tarefa, a professora organizou a turma em grupos de cinco ou quatro estudantes. Como era necessário escolher um grupo para ser observado, deixamos a critério da professora, que justificou a escolha argumentando que os estudantes do grupo escolhido se destacavam nas aulas. Os integrantes deste grupo eram Raquel, Lucas, Flávia, Fernando e João.

Os dados da presente pesquisa foram coletados em uma aula de Matemática, na qual os estudantes utilizavam material manipulável como o descrito anteriormente. Deste modo, essa aula foi analisada no sentido de compreender como os estudantes compartilharam o repertório da prática em questão, conforme é conceituado por Lave e Wenger (1991). Assim, focamos na análise da experiência social de um grupo de estudantes numa sala de aula como participantes de uma prática, observando as experiências vividas durante a prática social desse grupo, além de sua estrutura funcional, caracterizando-se, assim, uma pesquisa qualitativa (DENZIN; LINCOLN, 2005).

Consoante ao método de pesquisa, procedemos de maneira sistemática na coleta de dados, concebendo a observação, a entrevista e os documentos como procedimentos para a produção dos dados (LANKSHEAR; KNOBEL, 2008). Nesse caso, a observação foi utilizada como procedimento primário de coleta dos dados por permitir observar fatos, comportamentos e o próprio cenário da prática que caracteriza ação de valor na pesquisa qualitativa (ALVES-MAZZOTTI, 2002). A observação foi não-estruturada, pois o ambiente de pesquisa foi suficientemente aberto, ou pelo menos com a permissão dos responsáveis, tentando ao máximo possível apenas "ver” o que está ali para ser visto (LANKSHEAR; KNOBEL, 2008). Desse modo, foi possível "congelar" parte 
do evento no momento em que ele ocorreu, usando um dispositivo de gravação para capturar fala, comportamentos e expressões corporais.

A entrevista foi realizada com todos os integrantes do grupo observado, após o desenvolvimento da tarefa e teve duração média de 5 minutos. Esta entrevista foi pouco estruturada e não houve uma ordem rigorosamente estabelecida para as perguntas (ALVES-MAZZOTTI, 2002). Desse modo, os estudantes puderam falar livremente sobre cada pergunta feita pelo pesquisador. As perguntas eram direcionadas à compreensão do significado atribuído por eles aos eventos ocorridos, situações que não ficaram claras e processos realizados. No caso desta pesquisa, os documentos analisados foram os registros que os estudantes produziram durante $o$ desenvolvimento das tarefas (ALVES-MAZZOTTI, 2002).

Na análise dos dados, foi utilizada a Grounded Theory (CHARMAZ, 2009), que sugere uma análise em etapas. Entretanto, não estamos comprometidos com os pressupostos filosóficos assumidos nessa teoria, mas sim com o que é sugerido como procedimento de análise. Os dados foram transcritos por meio do processo de assistir os vídeos repetidas vezes. Assim, as transcrições foram organizadas em linhas, numeradas a partir de 1 e analisadas uma a uma, processo este denominado de análise linha a linha (CHARMAZ, 2009). A partir disso foram criados códigos, frases relativamente curtas, que resumiam as ações e falas dos estudantes, de modo a subsidiar a elaboração de classificações e categorias mais gerais. Essas foram chamadas de episódios, conforme apresentados na análise dos dados.

\section{Apresentação dos dados}

O episódio que será apresentado nesta seção foi originado das ações e falas dos estudantes, durante o desenvolvimento de uma tarefa referente às compreensões sobre o teorema de Pitágoras a partir da igualdade de áreas de figuras planas, a partir de triângulos e quadrado, efetuando a sobreposição de todas as áreas vermelha $(4 \times 4 \mathrm{~cm})$ e amarela $(3 \times 3 \mathrm{~cm})$ na área azul $(5 \times 5 \mathrm{~cm})$. O episódio foi criado seguindo a ideia básica de momento importante da aula associado aos códigos que possuíam assunto comum, no qual os estudantes estavam envolvidos em alguma discussão fazendo uso explícito ou implicitamente do material manipulável. A seguir, veremos o episódio e as análises.

\section{Episódio: Compartilhamento de símbolos, expressões e termos geométricos}

Neste episódio, o intuito é evidenciar alguns trechos em que os estudantes utilizavam símbolos, termos ou expressões geométricas ou que faziam referência a algum elemento geométrico e discutir como ocorre o uso desses elementos na prática social dos participantes. Os estudantes já 
estavam com os kits, descritos anteriormente. Nessa etapa, os estudantes chegaram à fase de cortar parte do material manipulável, sobrepor e justapor algumas delas (Figura 1). Nessa atividade, alguns símbolos surgiram no sentido de representar áreas, lados e catetos. Como exemplo, o símbolo $c^{2}$ foi utilizado para representar a área do quadrado amarelo de lado $c$.

Figura 1 - Recortes de quadrados amarelos e vermelhos

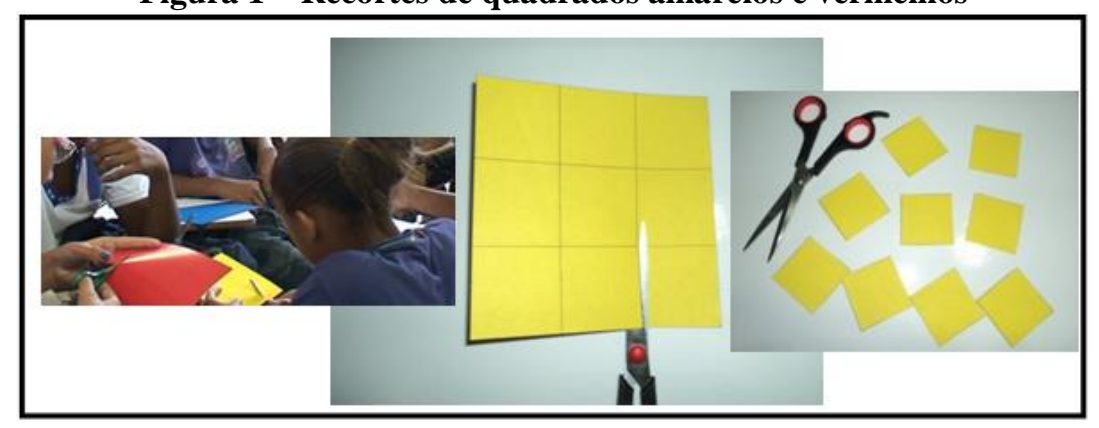

Fonte: Elaborada pelos autores

Feito isso, os estudantes puderam ver os objetos do kit cortados, alguns nas mãos e outros sobre o braço da cadeira, com expressões faciais que indicavam investigação, além de reconhecerem alguns elementos geométricos nos materiais manipuláveis e, consequentemente, introduzirem expressões, símbolos e termos durante o desenvolvimento da tarefa. A transcrição, a seguir, traz um pouco do momento em que eles começaram a tornar explícito esse reconhecimento.

(1) João:

(2) Professora:

(3) Fernando:

(4) Professora:

(5) Fernando:

(6) Professora:

(7) João:

(8) João:

(9) Fernando:

(10) Professora:
Aqui gente, triângulo... Lados, altura... [Segura os materiais nas mãos].

A gente já conhece esses lados, não é Fernando?

É o cateto...

Onde é cateto?

Aqui [Apontando para a hipotenusa do triângulo].

Agora vem cá, e esse daqui, esse azul, é de que lado do triângulo?

Hipotenusa!

Você vai ver, é o quadrado... Então é a soma dos quadrados dos catetos.

A área do triângulo retângulo é igual à área do quadrado...

É isso? A área do triângulo retângulo é igual à área do quadrado?

João demonstrou interesse em mostrar para o grupo que compreendeu o que estava no kit. Ao dizer isso, ele segurou o triângulo retângulo na mão e começou a apontar os lados e a altura do triângulo e os lados do quadrado sobre a mesa com o dedo indicador. Tudo foi atentamente ouvido pelos outros integrantes e consequentemente sua forma de se expressar foi reconhecida. Os demais integrantes tomaram os materiais em mãos e começaram a olhar como se quisessem verificar o que foi dito por João. Não é possível afirmar o quanto foi socializado das ideias desse membro, mas que essas ações, em forma de palavras, expressões, símbolos e gestos foram partilhados. Desse modo, cada membro pode corroborar e compartilhar do mesmo entendimento tido por João. 
As ações presentes nesse trecho, juntamente com outras ações e os termos lado, altura, triângulo e outros constituem o repertório da prática. Elas são compartilhadas talvez nem sempre diretamente, mas marcando certamente uma atmosfera comum àqueles participantes. Desse modo, quando João demarca alguns elementos que são do conhecimento dele, surge uma zona de reconhecimento grupal que engloba os outros membros. Além disso, quando ele faz uso dos materiais manipuláveis para apontar esses elementos, que são de uso comum do grupo, permite que os outros também visualizem o que ele chama de altura, lado, etc. Algumas interpretações não foram legitimadas pelo grupo quando, por exemplo, João anunciou lado e Fernando anunciou cateto quando deveriam dizer hipotenusa.

O termo cateto já ficou bastante familiar nas discussões dos estudantes. Nas linhas 9 e 10, podemos perceber que eles reconheceram a ideia de área nos materiais. Fernando entendeu a área do triângulo retângulo como a área do quadrado azul, possivelmente porque este possuía lado igual à hipotenusa do triângulo. Nesse momento, a professora mostrou para o estudante que tinha algo estranho no que ele tinha dito e demonstrou isso pedindo que ele sobrepusesse o triângulo no quadrado azul.

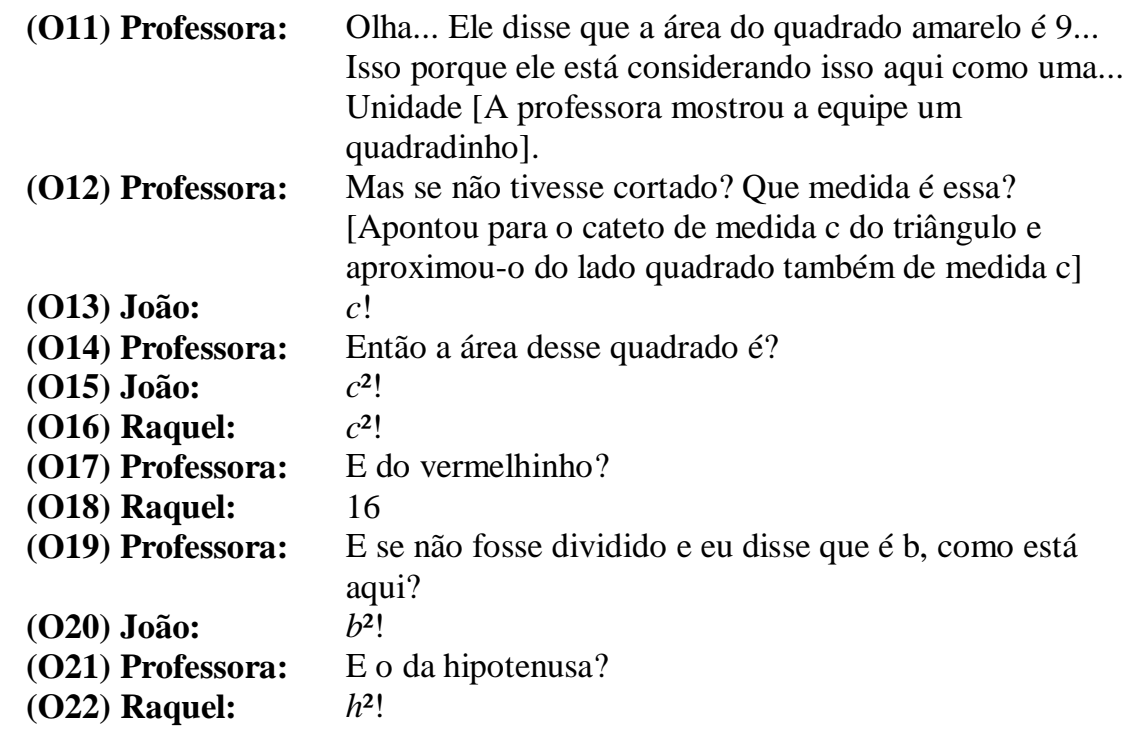

Até essa parte, os estudantes chegaram à conclusão de que cada área tinha uma ligação com o produto do respectivo lado do triângulo. Nesse ponto, foi fundamental o questionamento da professora juntamente com a ação de segurar e apontar cada objeto geométrico em questão para que os estudantes pudessem reconhecer elementos geométricos neles. Por exemplo, ao falar do quadrado amarelo, a professora segurava-o em suas mãos e apontava para seu lado quando ela perguntava o tamanho do lado. Ao falar da área do quadrado, ela gesticulava como se apontasse para toda a região da figura. 
Os estudantes passaram a falar sobre lados, nomearam-nos, referindo-se às figuras pelos nomes, como quadrado e triângulo retângulo, encontraram a área dos quadrados, $a^{2}, b^{2}$ e $c^{2}$. Esses símbolos $a^{2}, b^{2}$ e $c^{2}$, os termos e expressões utilizados fazem parte do repertório da prática social do grupo e possuem significados partilhados pelos membros. Desse modo, o episódio conseguiu retratar o uso compartilhado de um dos elementos que compõem o repertório da prática social do grupo de estudantes observados, sendo o uso partilhado pelos membros e os elementos destacados dotados de significados negociados, não necessariamente iguais, mas que se interrelacionam. Assim, símbolos, expressões e termos geométricos são compartilhados entre os membros do grupo como indispensáveis para manter os participantes unidos na perseguição dos objetivos do grupo.

\section{Discussão dos dados e conclusões}

O presente artigo teve como objetivo esboçar algumas formas de compartilhamento de repertório. $\mathrm{O}$ olhar sobre o repertório sugere a busca de compreender a manipulação de materiais manipuláveis como uma tarefa conjunta e intensa, na qual os participantes criam e utilizam o recurso da prática, isto é, o repertório de experiências, histórias e artefatos (os elementos físicos auxiliadores da prática) que reforçam o compromisso dos participantes com o grupo e que diferem esses membros de outras pessoas que não pertencem ao grupo (FRADE, 2003; LAVE; WENGER, 1991).

Nesse sentido, focamos nos modos de fazer as coisas, nas interpretações, nas ferramentas utilizadas pelos participantes, nos procedimentos, nas formas de linguagem/comunicação compartilhadas por um determinado grupo em plena participação em uma prática social (WENGER, 1998). Conforme entendemos, esses vários elementos, que são parte integrante da prática dos grupos observados, compõem o repertório da prática. No entanto, não significa que há consenso em todas as instâncias da prática.

O compartilhamento de simbologia, termos e expressões, referentes aos elementos geométricos, diz respeito aos símbolos, expressões e palavras que são necessárias para representar os elementos geométricos. Esses símbolos carregam significados que são negociados pelos membros do grupo (LAVE; WENGER, 1991). Nesse sentido, há modos de ver a prática por parte dos participantes que são partilhados e que implicam na convergência de significados. Assim, os símbolos possuem significados para os membros, mas são também elementos que já possuem significados históricos e culturalmente estabelecidos.

Nesse sentido, o símbolo $c^{2}$ tem inúmeras interpretações em vários contextos, mas, no contexto dessa prática, $c^{2}$ refere-se à área do quadrado amarelo ou ao quadrado do cateto menor do triângulo. Assim como os símbolos, as expressões utilizadas também têm significados que são negociados no contato social dos participantes com tais expressões. Utilizar, por exemplo, os termos 
quadrado, triângulo retângulo ou área, indica o modo (ou tem o significado) de pensar o quadrado como, no mínimo, relacionado com aquela representação do quadrado; pensar no triângulo retângulo indica pensá-lo relacionado com a sua representação e análogo às outras. Esses termos vão se configurando comuns aos membros, indicando o compartilhamento desses elementos e dos significados a eles negociados.

As tentativas de ajustar a fórmula do teorema de Pitágoras sugerem uma busca conjunta da expressão que fosse adequada àquela disposição das áreas menores na maior. Assim, as generalizações feitas sofreram avaliação do grupo no sentido de serem ou não validadas. Em outras palavras, os participantes queriam expressar o que haviam compreendido a partir daquela manipulação. Houve várias tentativas, muitas próximas da fórmula, outras nem tanto, mas que faziam algum sentido para quem lançava. Todavia, as que não se adequavam eram rejeitadas pelo grupo e sofriam modificações e, assim, marcavam a história do grupo como ideias não validadas.

Apesar de terem apontado a relação que representa o teorema, antes apresentaram várias incongruências. Cada uma das tentativas não reconhecidas fazia sentido apenas para eles. Nesse momento, a negociação de significado se mostrou mais implícita, pelo fato de vários elementos usados já terem seu significado negociado anteriormente. Isso sugere, por exemplo, que a expressão área do quadrado do cateto menor poderia estar se referindo à expressão área do quadrado amarelo ou mesmo quadrado do cateto menor ou simplesmente $c^{2}$.

Além disso, notamos que compartilhar o repertório da prática à qual se vincula é essencial para que haja, na íntegra, a participação de todos e estes tenham acesso aos afazeres oriundos da prática. Ter acesso a esses afazeres, então, diz respeito ao processo de compartilhar os modos de comunicação (termos, expressões, símbolos compartilhados), ao agir (tentativas compartilhadas), às ferramentas da prática (materiais manipuláveis, suas partes, mãos, tesouras, etc) e outros elementos que a compõem.

Concluímos, portanto, que os indivíduos participaram criando e utilizando o repertório da prática de modo compartilhado, tornando comuns os elementos integrantes desse repertório, conforme consta na perspectiva da aprendizagem situada por Lave e Wenger (1991). Esse movimento é essencial ao processo de tornar-se um participante, pois é vital ao participante envolver-se na rotina da prática (LAVE; WENGER, 1991). Nesse sentido, os membros ajustaram as diferentes interpretações das suas ações (SANTOS, 2004) e interrelacionaram os significados sobre os mesmos aspectos.

Além disso, em consonância com os resultados do estudo e dos trabalhos presentes na literatura, acreditamos estar trazendo subsídios para estudos que foquem em outros contextos, que não de salas de aula de matemática, ou mesmo para estudos que objetivem caracterizar outros 
modos de compartilhamento. Em relação à prática pedagógica dos professores de Matemática, este estudo pode apoiá-los no sentido de permitir olhar a sala de aula como campo de ações compartilhadas e desenvolvidas na prática, isto é, o repertório compartilhado.

\section{Referências}

ALVES-MAZZOTTI, A. J. O método nas ciências sociais. In: Alves-Mazzotti, A. J.;

Gewamdsznadjder, F. O método nas ciências naturais e sociais: pesquisa quantitativa e qualitativa. São Paulo: Pioneira, 2002. p. 147-178.

CHARMAZ, K. Constructing Grounded Theory: a practical guide through qualitative analysis. London: Sage, 2009.

CLEMENTS, D. H. 'Concrete' manipulatives, concrete ideas. Contemporary Issues in Early Childhood, v. 1, n. 1, p 1-16, 1999.

DENZIN, N. K.; LINCOLN, Y. S. Introduction: the discipline and practice of qualitative research. In: DENZIN, N. K.; LINCOLN, Y. S. (Ed.) Handbook of qualitative research. 3. ed. Thousand Oaks: Sage, 2005, p. 1-32.

FRADE, C. Componentes Tácitos e Explícitos do Conhecimento Matemático de Áreas e Medidas. 2003. 251 p. Tese (Doutorado em Educação) - Faculdade de Educação, Universidade Federal de Minas Gerais, Belo Horizonte, 2003.

LANKSHEAR, C.; KNOBEL, M. Pesquisa pedagógica: do projeto a implementação. Porto Alegre: Artmed, 2008.

LAVE, J.; WENGER, E. Situated learning: Legitimate peripheral participation. New York: Cambridge University Press, 1991.

MATOS, J. F. L. Aprendizagem e prática social: contributos para a construção de ferramentas de análise da aprendizagem matemática escolar. In: PONTE, J. P.; SERRAZINA, L. Educação Matemática em Portugal, Espanha e Itália. Atas da Escola de Verão - 1999 (Eds.). Lisboa: SEMSPCE, 2000. p. 65-94.

MOYER, P. S. Are We Having Fun Yet? How Teachers Use Manipulatives to Teach Mathematics. Educational Studies in Mathematics, v. 47, n. 2, p. 175-197, 2001.

PAIS, L. C. Uma análise do significado da utilização de recursos didáticos no ensino da Geometria. In: REUNIÃO ANUAL DA ANPED, 23., 2000, Caxambu. Anais... Caxambu: ANPED, 2000. 1 CD-ROM.

PASSOS, C. L. B.; GAMA, R. P.; COELHO, M. A. Laboratório de ensino de matemática na atuação e na formação inicial de professores de matemática. In: $16^{\circ}$ COLE-CONGRESO BRASILEIRO DE LEITURA, 16., 2007, Campinas. Anais... Campinas: ALB, 2007.

PASSOS, C. L. B. Materiais manipuláveis como recursos didáticos na formação de professores de matemática. In: LORENZATO, S. (Org.). O laboratório de ensino de matemática na formação de professores. São Paulo: Autores Associados, 2006. p. 77-92.

SANTOS, M. P. Encontros e esperas com os Ardinas de Cabo Verde: aprendizagem e participação numa prática social. 2004. 701 f. Tese (Doutorado em Educação e Didática da Matemática) - Universidade de Lisboa, Faculdade de Ciências, Departamento de Educação, 2004. WENGER, E. Comunities of Pratices Learning, Meaning, and Indentity. Cambridge: University Press, 1998. 